\title{
The Immune Concerns for Chronicity of Sars-cov-2 Infection in Man
}

\author{
Ibrahim M.S.Shnawa* \\ *Anesthesia Department, Hilla University College Rarengia ,Babylon And formal Professor \\ Emeritus .Department of Biotechnology, College of Biotechnology ,University of Qasim ,Qasim Babylon \\ Province ,IRAQ
}

\begin{abstract}
The objective of the present opinion was disclose some immune features of chronic sars-cov-2 human infection. The extension of sars-cov-2 infection manifestation up to 12 months or more beyond the onset of the clinical infection is considered to be chronic. The problem of chronicity gain its importance impart by the residence of infecting sars-cov-2 virus in a reserve organ and frequently releasing it to the blood circulation reaching other body parts causing continual stimulation of hosting immune system with an outcomes of an immune overreactions, immune weakening and immune mediated diseases. The immune features of the chronicity in covid-19 infections appeared to be different in different patients, though the presence of in-common ones. There was an array of the immune system behavior noted in such chronicity as; Prolonged adaptive immune activation and cellular exhaustion, weakening, over-reaction as well as inflammatory and immune tissue injuries. Gullain Barre autoimmune disease was currently documented to be induced by chronic sars-cov-2 virus infection.
\end{abstract}

Keywords: Chronicity, covid-19, disease ,immune, inflammation ,Sars.

DOI: $10.7176 / \mathrm{JHMN} / 86-04$

Publication date: February $28^{\text {th }} 2021$

\section{Introduction}

Fauci (2020). Described chronic covid-19 as "Long covid-19 is a phenomena that is really quite real and quit extensive(Parshley 2020).Sars-cov-2 virus human clinical infection can be ramified into acute and post -acute entities(Davido et al.2020). The post-acute entities gained several designations, such as ; persistence(Davido et al.2020,Greenhagh et al.2020),long( Global Auto Immune Institute ,2020), lasting (Marshall,2020), and Chronic (Zimmer,2020).Chronicity as a term for sars-cov-2 virus can be defined by the extension of the infection course up to 12 week or more beyond the onset(Greenhalgh et al.2020). The British Society of Immunology at Aug,2020.,briefing recommended to focus on understanding the biological mechanisms that derive the long term immune health consequences of sars-cov-2 infections and confirmed by similar holdings of the global autoimmune institute (Akbar \&Dunn-Walter 2020,Global Autoimmune Institute 2020). To date still the immune features of the covid-19 chronicity is in its infancy phase(Global Auto immune Institute 2020, Yelin et al.2020,Lolita et al.2020 ). The present opinion tried to focus onto the current views on the immune features of chronicity in covid-19.

\section{Immune Concerns of Chronic Viral Infections}

Chronic viral infections and chronic viral syndromes holds a unique challenge to the infected ,host. A state during which persistent replicating viruses outcompete or subvert the initial antiviral responses allowing the establishment of chronic infections that lead to continual stimulations for both of innate and adaptive immune response compartments both at the level of systemic and mucosal responses. Such events causes a profound reprogramming of the host immune system through attenuation and persistence of low grads of type I interferons, progressive loss or exhaustion of CD8 T cell function and specialization of CD4 T cells to produce interleukin 21 and promote humoral immune responses and immune regulation.

The in-vivo microenvironment witness to the epigenetic, transcriptional, post-transcriptional and metabolic changes forms the basis of this adaptive or recalibration of the immune cells to an emerging new environment in order to strike an often imperfect balance between the host and the virus pathogen(Zuniga et al.2015, Virgin et al.2009).During the chronic viral infection, effector $\mathrm{T}$ cells were self- limiting their responsiveness during persistent viral infection via IL10 dependent negative feedback loop(Parish et al.2014).

\section{The Current known Immune Concerns of Chronic Sars-cov-2 infection:Immune Concerns of Chronic Viral Infection}

The sars-cov-2 virus tried to gain foot hold in the host through finding port of entry, the nose ,mouth and/or eyes. Post to its entry to the upper part of respiratory tract then migrate to bronchus, acute infection phase initiated as tripartite mechanisms occur as; Viral mechanisms ,viral strategies and immune strategies. Viral mechanisms are; primary replication, spread, secondary replication, tissue damage in lung endothelium then in other tissues and shedding. Viral strategies include rapid replication, immune evasion, or subversion, immune privilege tissue 
damage. Host immune strategies expresses innate immune reactions ,antigen presentation, cytokine production, clonal lymphocyte expansion, antiviral effector mechanisms such as $\mathrm{T}$ cell functions and regulatory cell interaction .In this acute phase, viral and immune strategies compete for dominance .In the assumption that host survive, a decision point reached at which the infection is either cleared or becomes chronic.

This decision point may be reached very early in the infection process for sars-cov- 2 that can establish a latent infection In which case the infection is permanent in spite of the acute infection course .If recovery occurs the immune system must reset by clearing the viral antigens and re-sustaining the immune homeostasis. If the balance shits towards chronic infection, then a new set of both viral and host strategies as continuous intermittent release of viral antigens ,tissue damage, altered immune system and altered homeostasis. In which case, two events do happened .First the viral strategies like continuous replication ,latency ,niche specific evasion gene and niche specific regulatory gene expressions and possible mutation finally search for immune- privileged niches .Second the immune effects may be evident as dampen responses, chronic activation, lung and other organ immunonpathology, lymphocyte function or dysfunction and repertoire contraction(Vabret et al.2020,Sherina et al.2020,Zungia et al.2015, Virgin et al.2009 ). The hypothetical deduced immune mechanism of chronicity in covid - 19 was the implication of immune regulation versus dys-regulation as well as activated immune system response to the virus leading to neurological, cardiovascular respiratory these will lead to the initiation of chronic symptoms(Alberta Health Services .2020).

\section{Immune System Weakening:}

The USA epidemiologic record of sars-cov-2 human clinical infections has shown disproportionate impacts communities of color as 33\% Hispanic, $22 \%$ black\&1,3 American Indians/Alaska natives(Global Autoimmune Institute,2020).Chronic viruses and chronic viral infections are illnesses that have been developed and remain alive in the body without patients even being aware of them and can weaken immune system and leave it susceptible to infectious diseases(Spurlock 2020). Some works on the immunology of covid-19 have been documented weakening of the immune system appeared as a form of immunodeficiency and susceptibility to microbial infections since chronicity may shed a suppressive influences towards weakening of their immune system activities due to reduction in production of interferons as in the case of mers(Marshall,2020).Sar-cov-2 human infection render the infected host in severe immunosuppressed state(Remy et al.2020).

\section{Immune System Overreaction :}

In acute phase sars-cov-2 severe infection forms the immune system of the complaining patients may suffer from; cytokine storm(Badawi 2020),microthrombi (Middleton et al.2020),MAIT cell dynamicity(Parrot et al.2020),complement unrestrained activation(Noris et al.2020)and autoimmune B cell phenocopy producing Anti -inteferon Type I antibodies (Bastard et al.2020).In chronicity phase ,however, the immune system of the infected patient is over-reacted and trigger severe inflammation throughout the body(Marshall 2020) and the committed immune cells produce enhanced INF gamma and other cytokines as a sign of immune over-reaction and it is possible that the immune system stuck in an over-reactivity state in which the pathogen stay in a stealth state in a reserve organ gaining shelter and chances of frequent release to blood aggravating the unceasing immune responses(Zimmer et al.2020)Though the hyperactive immune responses may be in association with both severe chronic infected patients and in normal individual as well(Global Autoimmune Institute 2020,Lolita et al.2020).Chronicity may be associated with prolonged B and T cell activation up to eight months and cellular exhaustion (Mudd \& Remy 2021).

\section{Pathologic Autoimmune Responses:}

The body immune responses to sars-cov-2 virus is the cornerstone of the story of the chronic infection phase. Some healthy individuals have complaining covid-19 followed by extended disease manifestation which may trigger the potential development of autoimmune disease(Global Institute of Autoimmunity 2020).On chronicity the virus eradicated from the body but leave behind parts of the viral RNA in a reserve organ. These parts of RNAs or its translated protein, once reached the body B and/or T cells could set for immune responses and stayed in an immune chaos un-leached by the presence of the virus in their continuum triggering an autoimmune responses such as that like Gullain Barre syndrome, in which the viral protein simulate host proteins attack macrophages. The attacked macrophages then present it to $\mathrm{T}$ cells. Auto reactive $\mathrm{T}$ cells evolved and the condition of the immune system be permissive so that such auto-reactive $\mathrm{T}$ cells to escape immune surveillance mechanisms and express pathologic autoimmune responses .In other mechanism may be the viral RNA or viral protein slip in to the mitochondria and destroyed its metabolic functions making a condition like that of autoimmune reactions(Zimmer 2020). The humoral and cellular immune events during autoimmune disease impacts the patient immune system and render it impaired(Global Autoimmunity Institute 2020).Chronic Sarscov-2 infection found and documented in association Gullain Barre GBS syndrome in which the prototype virus triggered autoimmune disease as GBS, necrotizing myositis and encephalopathies (Dalakas 2020).The immune 
features of GBS were depicted, in Table -1 .

Table 1. Molecular Immune Features of Chronic Covid-19 induced GBS(Dalaks-2020).

Immune demyelination of neurons

Elevation of CSF proteins

Elevated Acute phase protein $\mathrm{C}$

Lymphocytopenia

Thrembocytopenia

restore to the norm by intravenous Immunoglobulin

Anti-ganglgioside antibodies

Sars-cov-2 RNA and RNA genes +/-

\section{Molecular Immune Mechanisms:}

During sars-cov-2 infection events within the human body, it leaves unique micro-RNA sequences in the blood stream that can pose to change in the expression of the genes coding the immune responses and may influence an epigenetic changes in the gene responsible for downstream metabolism inducing an alteration in the protein metabolites which might lead to an autoimmune responses(Zimmer 2020).In a current study conducted by a group of workers were reported a strong positive selection on sars-cov-2 during convalescent plasma therapy and identifying spike protein mutations; $\mathrm{D} 776 \mathrm{H},{ }^{\wedge} \mathrm{H} 69 / \wedge \mathrm{V} 70$ as a broad antibody resistance mechanism against commonly occurring antibody response to sars-cov-2(Kemp et al.2020).

\section{Immune Concerns of Severe Sars-cov-2 and Ageing:}

Immuno-senescence is an age related change to the adaptive immune system that results in an impaired ability to combat infections ( Lolita et al.2020,Oh et al.2019).Severe infection cases in an ageing subjects may undergoes an inefficient transition from innate to adaptive responses in patients whom have prolonged INF gamma stimulated genes and reduced antigen presentation genes as compared to non-senescence sars-cov-2 cases(Cameron et al.2020). The innate immune system responses to the infection directly contribute to elevate the inflammatory and the impaired adaptive immune responses in the ageing adults(Zhao et al.2020).

\section{The Suggested Determinants of Chronic Human Sars-cov-2 Infections:}

From a careful review to the current published works on the covid-19 chronic infection one can suggest the followings;

- It persist to 12 weeks or more beyond the onset

- Shows elevated, acute phase protein C, interferon I and Gamma.

- Some shows elevated antinuclear factor and ganglioside autoantibodies

- Shows persistent inflammatory and immune responses even in absence of the infection

- lymphocytopenia and thrombocytopenia

- Leukocytosis

- Viral RNA tissue reserve, and virus RNA tissue resident genes.

- Whole marks of chronic tissue immunopathology in patients biopsy and autopsy samples

\section{Chronicity Immune Features:}

The evident marked immune features of the chronic covid-19 were outlined in the followings;

- Chronicity and /or ageing negatively impacts the functions of human immune system. Some patients may have weakening immune system.

- $\quad$ Presence of Sars-cov-2 specific memory B and T lymphocytes

- Persistent specific IgG

- Leukocytosis, lymphocyte-penia ,thrombocytopenia

- $\quad$ Elevated; CRP ,Interferon I and gamma

- Persistent B and T cell activation and cellular exhaustion

- In Covid-19 triggered Autoimmune Diseases ;elevated ANF and Antiganglioside antibodies.To have a clue to immune features of covid-19 in comparative manner as noted in the, Table -1 . 
Table 2. Immune features of covid-19 acute, severe acute and chronic forms.

\begin{tabular}{|c|c|c|c|}
\hline Features & Acute & Severe Acute & Chronic \\
\hline $\begin{array}{l}\text {-Sars-cov-2 antibody } \\
\text { iso-type }\end{array}$ & $\operatorname{IgM}, \operatorname{Ig} \mathrm{A}$ & $\operatorname{IgM}, \operatorname{Ig} \mathrm{A}$ & $\mathrm{IgG}$ \\
\hline $\begin{array}{l}\text {-Duration } \\
\text {-Virus } \\
\text { Neutralizing }\end{array}$ & $\begin{array}{l}3-6 \text { moths } \\
+\end{array}$ & Dependent on severity outcome & $?$ \\
\hline Autoantibodies & $?$ & Rare anti type Interferons & $\begin{array}{l}\text { Rare antinuclear factor, Anti- } \\
\text { gangeliosides }\end{array}$ \\
\hline Memory B cell & $\begin{array}{l}6-8 \\
\text { months }\end{array}$ & Dependent on severity outcome & $?$ \\
\hline MAIT & Functional & $\begin{array}{l}\text { Dynamic recruitment between } \\
\text { circulation and airways }\end{array}$ & $?$ \\
\hline Leukocytosis & + & + & +1 \\
\hline Lymphocytopenia & $?$ & ++ & ++ \\
\hline Throbocytopenia & $?$ & $+/-$ & + \\
\hline
\end{tabular}

\section{Laboratory Biology:}

Expert efforts and recommendations(Davido et al.2020,Greenhalgh et al. 2020,Dalaks 2020) concerning the diagnostic laboratory biology of chronic sars-cov-2 infection were outlined in Table -3

Table 3 :Clinical Investigation of Chronic Covid -19 and its induced chronic diseases

\begin{tabular}{|l|lr|}
\hline $\begin{array}{l}\text { Chronic Covid-19 induced } \\
\text { Disease }\end{array}$ & Diagnostic Investigations & \\
\hline Autoimmune & $\begin{array}{l}\text { Serology, ANF, lymphocyte count, WBC count, thrombocyte } \\
\text { count,CRP,NAT. }\end{array}$ & $\begin{array}{l}\text { Serology , anti-ganglioside antibodies, lymphocyte count ,WBC, } \\
\text { thrombocyte count } \\
\text { CSF proteins, NAT. }\end{array}$ \\
\hline Neural & Serology, CRP,lymphocyte count,WB C count, troponin, ferritin,NAT \\
\hline Fatigue Syndrome & $\begin{array}{l}\text { Serology ,CRP ,lymphocyte count ,WBC count ,CRP, } \\
\text { troponin ,Ferritin,NAT }\end{array}$ \\
\hline
\end{tabular}

\section{Conclusion:}

The immune system in covid-19 chronicity is trained for an array continual tuned biological events and mechanisms like inflammatory, immune, allergic, suppressive and autoimmune responses. By this it will be either weakened or over-reacted. The overreacted is either inflammatory cytokine induced or of autoimmune nature leading to pathological auto immune conditions. Gullain Barre syndrome is a rare documented Covid-19 triggered autoimmune condition.

\section{References}

Akbar,A. \&Dunn-Walter,D.(2020).Covid-19 immunology briefing note: What we know about long term health consequences and priorities for research. Press release. Society news, immunology in news.

Alberta Health Services(2020).Covid -19 Scientific and Advisory group. Rapid evidence report.Nov.23.2020.

Badawi ,A.(2020).Hypercytokinemia and host pathogen interactions .J .Infect. Res. 13:255-261.

Bastard ,P., Rosen,L.B.,Zhang,Q.,Michailidis,E.,Hoffmann,H-H.(2020).Auto antibodies against Type I interferons in patients with life threatening Covid-19.Scince.10.1126/science.abd.4585.

Cameron,M.J.,Bermejo,J.F.,Danesh ,A.,Muller,M.P.,Kelvin,D.J.(2020).Human immunopathogenesis of severe acute respiratory syndrome (sars ).Virus. Res .133:130-39.

Dalakas,M.C.(2020).Gullain-Barre syndromes: the first documented covid-19 triggered autoimmune neurologic disease .Neurol .Neuro-immunol. Neuroinflamm.e781.doi.1212/NXI.0000000000000781.

Davido,B.,Seang,S.,Tubiana,R.,deTruchis,P.(2020).Post covid-19 chronic symptoms:A post infection entity.Clin.Microbial.Infect.26:1448-1449.

Global Autoimmune Institute.(2020).Covid-19 and autoimmune diseases :What we know now. Environmental Health.Oct.24.2020

Greenhalgh,T.,Knight,M., A Court,C. ,Buxton,M .,Hussain,L.(2020). Management of postacute covid-19 in primary care. BMJ. $370 . m 3026 /$ doi.1136/bmj,m2026.1-8.

Kemp,S.A.,Collier,D.A.,Datir,R.,Gayed,S.,Juhan,A.(2020).Neutralizing antibodies derive spike protein mediated 
sars-cov-2 evation .MedRxiv .nonpeer reviewed preprint. made available underCC-By-NC-N $P .4$. International license.

Lolita,S.\& Watson,J.D.(2020).Underlying vulnerabilities to the cytokine storm and adverse covid-19 outcomes in the ageing immune system. J.Gerantol.:Medical Science.20(20):1-6.

Marshall,M.(2020).Covid-19 lasting misery.Nature.585:339-341.

Middleton,E.A.,He,X-H,Campbell,R.A.,Ng,D.,Savatore ,S.P. et al. (2020). Neutrophil extracellular traps contribute to immune-thrombosis in covid-19 acute respiratory distress syndrome.Blood.136(10):1169-1179.

Mudd,P.A.\& Remy,K.E.(2021).Prolonged immune activation in covid-19: implication for maintenance of long term immunity? J.Clin .Invest. 131 (1):e143928.

Noris,M.,Bengni,A.,Remuzzi,G.(2020).The case of complement activation in covid-19 multiorgan impacts. Kidney International.98:314-322.

Oh, S.T. ,Lee ,J.K., Shin ,O.S.(2019).Ageing and the immune system, the impact of immune-senescence on viral infection, immunity and vaccine immunity.Immu.Netw.19:e37.doi.10.4110/in2019.e37.

Parish,I.A.,Marshall,H.D.,Staron ,M.M. ,Lang ,P.A.(2014).Chronic viral infection promotes sustained TH1 derived immune-regulatory IL10 via BLMP-1.J.clin.Invest.124(8):3455-3468.

Parshley ,L.(2020). The many strange long term symptoms of covid-19,explained.Vox.com,Dec.15th.2020.

Remy,K.E.,Mazar,M.Stricker,D.A.,Ellebedy ,A.H., Walton, A.H.et al.(2020).Sever Immunosuppression and not cytokine storm characterize Covi-19 infection .JCI Insight .5(17):e140329 .doi.org/10.1172 / jci. insight.140329.

Sherina,N.et al.(2020).Persistence of Sars cov-2 specific B and T cell responses in convalescent covid-19 patients 6-8 months following infection.BioRixv.doi.org/10.1101/2020.preprint not certified by peer review.

Superlock, M.(2020).Chronic viruses and chronic viral syndromes .Renewed Vitality

Vabret,N. ,Briton,G.C. ,Gruber,C. ,et al.(2020).Immunology of Covi-19:Current state of Science.Immunity52:910-941.

Virgin,H.W.,Wherry E.J. ,Ahmed, R.(2009).Redefining chronic viral infection. Cell.138:30-51.

Yelin,D.,Writheim,E.,Vetter,P.,Kalil, A.C.(2020).Long term consequences of covid -19:Research need .Lancet/infection.20:1115-1116.

Zhao ,C. ,\&Zhao, W.(2020).Inflammo-some - a key player in the antiviral responses.Front.Immunol.11:211.doi.10.3389.fimm.2020.00211.

Zimmer, K.(2020).Could covid-19 trigger chronic In people. The scientists/ news \& opinion.July.17.2020.

Zungia,E.,Nacal,M.,Lewis,J.M.,Harker, J.A.(2015).Innate and adaptive regulations during chronic viral infections.An.Rev.Virol.2:573597. 